\title{
EDITORIAL
}

\section{Breaking News...}

\section{Solymosi}

Published online: 15 August 2014

(C) Springer-Verlag Berlin Heidelberg 2014

Just before printing the current issue, we received the news of the latest journal list featuring the impact factor for 2013 (Thomson Reuters Journal Citation Reports ${ }^{\circledR}$ 2013). We don't want to keep the good news all to ourselves: Our impact factor has increased yet again!

A year ago, we wrote "We're on the Right Path..." [1]. The current list confirms this trend: The impact factor of Clinical Neuroradiology has now climbed to $\mathbf{1 . 6 1 5}$.

Impact Factor Trend Graph:

Clinical Neuroradiology

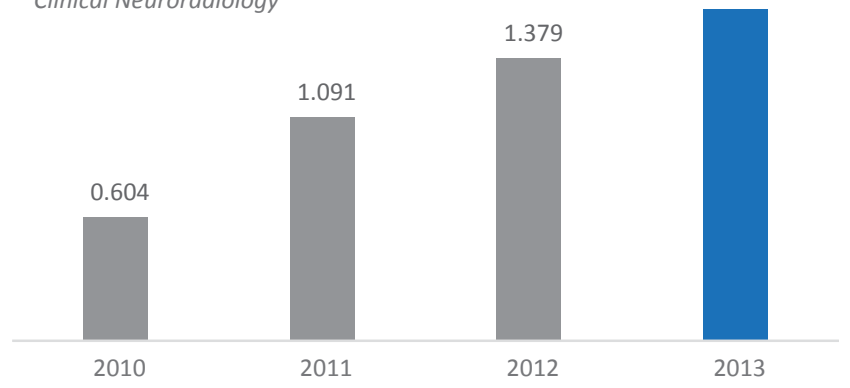

We would like to thank our authors for the high quality of their manuscripts. Only excellent works get cited, and these citations determine a journal's impact factor. Thus, we hope that you will continue to provide us with such outstanding work!

For our part, the Editorial Board will, of course, work hard to handle your submissions quickly and objectively, and to support you during the peer-review process.

\section{References}

1. Solymosi L. We're on the right path.... Clin Neuroradiol. 2013;23:173.
This increase is not due to a general rise in the impact factors of all the journals in the two categories where Clinical Neuroradiology is also listed, since our journal managed to move up in both rankings.

Our journal moved up seven places in the highly competitive "Clinical Neurology" category, and eight places in the "Radiology, Nuclear Medicine \& Medical Imaging" category-ample proof that Clinical Neuroradiology can definitely compete with other journals.

L. Solymosi $(\bowtie)$

Department of Neuroradiology, University Würzburg, Würzburg, Germany

e-mail: solymosi@neuroradiologie.uni-wuerzburg.de 